\title{
Effect of AS-35 on Agonist-Induced Contractions and the Resting Tonus of Airway Smooth Muscles and the In Vitro Release of Chemical Mediators from Passively Sensitized Lung Fragments from Humans and Guinea Pigs
}

\author{
Shigekatsu Watanabe-Kohno, Kiyoshi Yasui, Eiichi Ohkawa, Hideki Yamamura, \\ Michiaki Horiba ${ }^{1}$, Koji Inoue ${ }^{1}$ and Katsuya Ohata \\ Department of Pharmacology, Kyoto Pharmaceutical University, 5 Misasagi-Nakauchi, Yamashina, Kyoto 607, Japan \\ ${ }^{1}$ Department of Pneumology, Ogaki Municipal Hospital, 4-86 Minaminokawa, Ogaki 503, Japan \\ Received December 18, 1991 Accepted March 26, 1992
}

\begin{abstract}
Effects of 9-[(4-acetyl-3-hydroxy-2-n-propylphenoxy)methyl]-3-(1H-tetrazol-5-yl)-4H-pyrido [1,2-a]pyrimidin-4-one (AS-35) on the resting tonus or contractions induced by agonists, such as leukotriene (LT) $\mathrm{D}_{4}$ and specific antigen of isolated guinea pig tracheas or human bronchi, and the in vitro anaphylactic release of histamine and LTs from human lung fragments were investigated and compared with the effects of FPL 55712 and disodium cromoglycate. AS-35 as well as FPL 55712 did not affect the contractions induced by acetylcholine and histamine of the isolated guinea pig trachea. However, the compound at relatively low concentrations obviously inhibited contractions induced by $\mathrm{LTD}_{4}$, and the antagonistic activity was stronger than that of FPL 55712. Treatment of the isolated human bronchus with AS-35 tended to induce the inhibition of both LTD $_{4^{-}}$and antigen-induced contractions and the relaxation of the resting tonus in a concentration-dependent manner. The inhibitory potency at $10^{-6} \mathrm{~g} / \mathrm{ml}$ was slightly stronger than that of FPL 55712 , but this was not statistically significant. The anaphylactic release of histamine and LTs from the lung fragments appeared to be inhibited by the treatment with AS-35 5 min prior to the antigen challenge. From these results, it is suggested that AS35 is effective against allergic asthma through antagonism towards peptide-LTs released anaphylactically in addition to inhibition of the chemical mediator release.
\end{abstract}

Keywords: AS-35, Anaphylaxis, Leukotriene $\mathrm{D}_{4}\left(\mathrm{LTD}_{4}\right)$, Bronchus (human), Lung (human)

The pathogensis of asthma is considered to involve many mediators such as histamine, leukotrienes (LTs), prostaglandins, throboxane $\mathrm{A}_{2}$, platelet activating factor, etc. Of these mediators, peptide leukotrienes ( $\mathrm{p}$ LTs): $\mathrm{LTC}_{4}, \mathrm{LTD}_{4}$ and $\mathrm{LTE}_{4}$ being the main components of the slow reacting substance of anaphylaxis (SRS-A), have been proposed as the important mediators in asthma (1) because of their pharmacological properties of causing potent airway smooth muscle contraction (2), extravasation of plasma (3) and mucus hypersecretion (4). For these reasons, a p-LT antagonist would be expected to be effective against asthma. FPL 55712, a competitive antagonist of SRS-A, was first reported in 1973 (5). Unfortunately, however, it was later proven to have a very short half-life after administration (6).
AS-35 has been developed as an orally active p-LT antagonist (7). The pharmacological studies on AS-35 using guinea pigs revealed that the compound obviously antagonizes p-LT-induced contraction of isolated airway smooth muscle (7).

In the present study, we examined the effect of AS35 on agonist-induced contraction and the resting tonus of the trachea or bronchus and the in vitro anaphylactic release of chemical mediators from lung fragments from humans and guinea pigs.

\section{MATERIALS AND METHODS}

Drugs

Drugs used and their sources were as follows: AS-35 (Tokyo Tanabe Pharm., Tokyo; see Fig. 1 for its chem- 


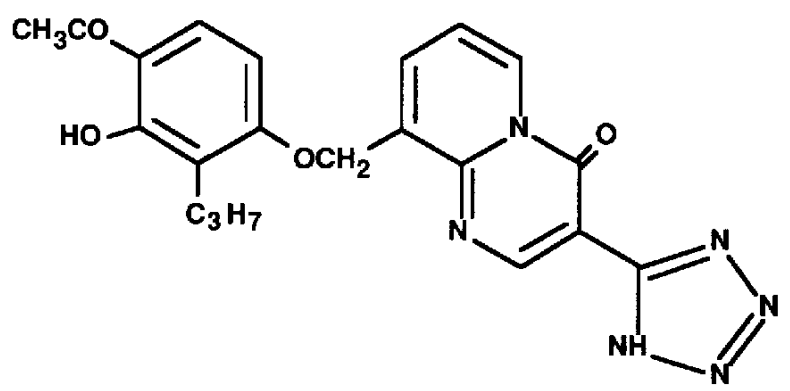

Fig. 1. Chemical structure of AS-35, 9-[(4-acetyl-3-hydroxy-2-npropylphenoxy)methyl]-3-(1H-tetrazol-5-y1)-4H-pyrido[1,2-a]pyrimidin-4-one (molecular weight: 420.4 ).

ical structure), FPL 55712 (molecular weight: 520.5) and disodium cromoglycate (DSCG) (molecular weight: 492.4) (Fisons, Loughborough). AS-35 and FPL 55712, and DSCG were dissolved in $N, N$-dimethylformamide and physiological saline, respectively.

\section{Reagents}

Reagents and their sources were as follows: gelatin (Merck, Darmstadt), $N$-(2-hydroxyethyl)piperazine- $N$ '2-ethanesulfonic acid (HEPES; Nacalai Tesque, Kyoto), $l$-isoproterenol (Sigma Chem., St. Louis), Lcysteine $\cdot \mathrm{HCl} \cdot \mathrm{H}_{2} \mathrm{O}$, dextran, acetylcholine chloride (ACh), histamine dihydrochloride, charcoal and $\mathrm{LTD}_{4}$ (Wako Pure Chem., Osaka), radioactive $\left[14,15-{ }^{3} \mathrm{H}(\mathrm{N})\right]-$ $\mathrm{LTB}_{4}$ and $-\mathrm{LTC}_{4}$ (New England Nuclear, Boston), liquid scintillation cocktail (RIAfluor, New England Nuclear, Boston).

Rabbit anti-LTC 4 plasma, which had a high crossreactivity to $\mathrm{LTD}_{4}(100 \%)$ and $\mathrm{LTE}_{4}(34 \%)$, was obtained in our laboratory by immunizing rabbits with LTC $_{4}$-conjugated Ascaris suum extracts.

\section{Physiological solution}

Modified Tyrode's solution (Tyrode's solution) was used as a physiological solution. The composition of the solution was $137 \mathrm{mM} \mathrm{NaCl}, 2.7 \mathrm{mM} \mathrm{KCl}, 0.37 \mathrm{mM}$ $\mathrm{NaH}_{2} \mathrm{PO}_{4}, 0.49 \mathrm{mM} \mathrm{MgCl}_{2}, 1.8 \mathrm{mM} \mathrm{CaCl}_{2}, 5.6 \mathrm{mM}$ glucose and $12 \mathrm{mM} \mathrm{NaHCO}$.

\section{Human atopic serum}

Human atopic serum (supplied by Drs. T. Shida and Y. Yanagihara of the National Sagamihara Hospital, Sagamihara), which possessed a radioallergosorbent test value of over $30 \%$, was used after 5-fold dilution with $\mathrm{Ca}^{2+}$-free Tyrode's solution.

\section{Mite antigen}

Mite extracts (from Dermatophagoides farinae, supplied by Dr. H. Nagai of Gifu Pharmaceutical Universi- ty, Gifu) were dissolved in physiological saline at a concentration of $10^{-3} \mathrm{~g} / \mathrm{ml}$ and stored at $-80^{\circ} \mathrm{C}$ until use.

\section{Animals}

Male, Hartley guinea pigs weighing $560-1,230 \mathrm{~g}$ (purchased from Japan SLC, Hamamatsu) were used.

Macroscopically normal human lung portions were obtained at the time of resection for carcinoma and used as soon as possible for bronchial and lung fragment experiments.

Bioassay of isolated tracheal or bronchial smooth muscles

Preparation of isolated tracheal chain strips: Guinea pigs were exsanguinated following a blow on the head, and then the trachea was removed. The organ was split longitudinally through the ventral cartilage. The tracheal preparation consisting of 3 segments, each of which was two-cartilage-rings-wide and connected with a surgical adhesive (ethylcyanoacrylate, Aronalpha A Sankyo, Sankyo, Tokyo) end-to-end, was suspended in a Magnus bath.

Preparation of isolated bronchial strips: The human bronchi, inner diameter of $1-3 \mathrm{~mm}$, were carefully removed from lung parenchyma and cut spirally to make a strip of $2 \mathrm{~mm}$ in width and $2 \mathrm{~cm}$ in length.

Measurement of movement of the isolated tracheal or bronchial smooth muscles: The guinea pig tracheal or human bronchial strip was suspended in a Magnus bath. Conditions of the experiments were as follows: temperature, $37 \pm 0.1^{\circ} \mathrm{C}$; loading weight, $300 \mathrm{mg}$ and volume of Magnus bath, 3 or $5 \mathrm{ml}$. Movement of the smooth muscle was recorded isotonically (isotonic transducer: TD-112S and recorder: RJG-4124, Nihon Kohden, Tokyo) through amplification (amplifier: HA-601H, Nihon Kohden, Tokyo). Each experiment was started after almost constant contractions of the preparation by repeated application of the final concentration of $10^{-6}$ $\mathrm{g} / \mathrm{ml}$ ACh were observed.

The contraction induced by $A C h$, histamine or $L T D_{4}$ : Following observation of almost equal contractions by $10^{-6} \mathrm{~g} / \mathrm{ml} \mathrm{ACh}, 10^{-6} \mathrm{~g} / \mathrm{ml}$ histamine or $10^{-8} \mathrm{~g} / \mathrm{ml}$ $\mathrm{LTD}_{4}$ of the guinea pig trachea or human bronchus, the influence of AS-35 or FPL 55712 on these agonists-induced contrations was examined, where the drug was added $5 \mathrm{~min}$ prior to the agonist addition. The contractions induced by $\mathrm{LTD}_{4}$ at $10^{-8} \mathrm{~g} / \mathrm{ml}$ were almost equal in magnitude to those induced by $10^{-6} \mathrm{~g} / \mathrm{ml} \mathrm{ACh}$ or histamine in the guinea pig trachea. Contractile responses by the agonist with or without the drug in the human bronchial experiments were each expressed as a $\%$ of the contraction induced by $10^{-6} \mathrm{~g} / \mathrm{ml} \mathrm{ACh}$, and those in the guinea pig tracheal experiments were ex- 
pressed as $\%$ of antagonism by the drug.

The resting tonus: The influence of drugs on the resting tonus of bronchi was observed for $25 \mathrm{~min}$, and the preparation was further treated with $10^{-6} \mathrm{M}$ isoproterenol without washing to obtain the maximum relaxation.

The antigen-induced contraction: Passive sensitization of the isolated bronchus was carried out by the incubation with a 5-fold dilution of human atopic serum (2 $\mathrm{ml} /$ preparation) at $37^{\circ} \mathrm{C}$ for $1.5 \mathrm{hr}$. After completion of the passive sensitization, the preparation was suspended in a Magnus bath. Drugs were added $5 \mathrm{~min}$ prior to the challenge with $5 \times 10^{-6} \mathrm{~g} / \mathrm{ml}$ of antigen.

\section{Release of histamine and LTS from passively sensitized} lung fragments

Preparation, passive sensitization and antigen challenge of lung fragments: The procedure from preparation to chemical mediator release of human lung fragments was described elsewhere (8).

In brief, the chopped lung parencymal fragments of about $1 \times 2 \times 0.7 \mathrm{~mm}$ in size were passively sensitized with a 5-fold dilution of the mite-sensitive human atopic serum. After washing with Tyrode's solution, the fragments were suspended in Tyrode's solution and challenged with specific antigen. Drugs were added $5 \mathrm{~min}$ before antigen provocation.

Histamine and LT assays: Histamine in the anaphylactic supernatant was fluorometrically assayed after extraction according to the method of May et al. (9). For the estimation of histamine contents in the tissue, the lung fragments, which had not been challenged with antigen, were treated in a boiling water bath for $10 \mathrm{~min}$ following addition of $2 \mathrm{ml} / 100 \mathrm{mg}$ wet tissue of $1 \%$ perchloric acid. After adding an equal volume of physiological saline and centrifugation at $1,700 \times \mathrm{g}$ for $20 \mathrm{~min}$ at $4^{\circ} \mathrm{C}$, histamine in the supernatant was measured as described above.

LTs in the anaphylactic supernatant were assayed by
RIA after partial purification as reported previously (10); the LT specimen, which was partially purified with an Amprep C-18 reversed phase column using increased concentrations of ethanol followed by removal of the ethanol under reduced pressure, was subjected to RIA.

Amounts of $\mathrm{LTB}_{4}$ and p-LTs estimated were expressed as those of immmunoreactive (i-) $\mathrm{LTB}_{4}$ and i-L. $\mathrm{TC}_{4}$, respectively.

\section{Statistical analyses}

Statistical analyses were conducted by the paired or unpaired $t$-test. $\mathbf{P}$ values under 0.05 were taken as significant.

\section{RESULTS}

\section{Effects on the isolated airway smooth muscle}

Effects on the agonist-induced contraction: The influence of AS-35 on the contractions of the isolated guinea pig trachea and human bronchus induced by ACh, histamine or LTD $_{4}$ is shown in Table 1 and Fig. 2 , respectively.

In the guinea pig trachea, pretreatment of AS-35 as well as FPL 55712 at the final concentration of $10^{-6}$ $\mathrm{g} / \mathrm{ml}$ hardly affected the contractions by either $\mathrm{ACh}$ or histamine. However, the contraction by $10^{-8} \mathrm{~g} / \mathrm{ml}$ $\mathrm{LTD}_{4}$ was significantly inhibited by the compound at 3 $\times 10^{-7} \mathrm{~g} / \mathrm{ml}$. The inhibitory potency was stronger than that of FPL 55712 .

AS-35 also inhibited or tended to inhibit the contraction of the isolated human bronchus by $10^{-8} \mathrm{~g} / \mathrm{ml}$ LTD $_{4}$ concentration-dependently. When compared at $10^{-6} \mathrm{~g} / \mathrm{ml}$, the inhibitory potency of AS-35 was slightly stronger than that of FPL 55712, although this was not statistically significant.

Effects on the resting tonus: On the resting tonus of the isolated human bronchus, AS-35 induced concentra-

Table 1. Effect of AS-35 and FPL 55712 on the contractions induced by acetylcholine (ACh), histamine and leukotriene (LT) $\mathrm{D}_{4}$ in isolated guinea pig trachea

\begin{tabular}{lcc}
\hline & \multicolumn{2}{c}{$\%$ of antagonism (mean $\pm \mathrm{S} . \mathrm{E})}$. \\
\cline { 2 - 3 } Agonist $(\mathrm{g} / \mathrm{ml})$ & \multicolumn{1}{c}{ AS-35 } & FPL 55712 \\
\hline ACh $\left(10^{-6}\right)$ & $0.3 \pm 0.16(\mathrm{~N}=7)$ & $2.5 \pm 0.98(\mathrm{~N}=8)$ \\
Histamine $\left(10^{-6}\right)$ & $0.6 \pm 1.02(\mathrm{~N}=8)$ **** & $0.6 \pm 0.80(\mathrm{~N}=8)$ \\
LTD $_{4}\left(10^{-8}\right)$ & $51.1 \pm 5.49(\mathrm{~N}=15) \# \# \#$ & $14.8 \pm 3.31(\mathrm{~N}=14)^{* * *}$ \\
\hline
\end{tabular}

Either AS-35 or FPL 55712 was administered at the final concentrations of $10^{-6} \mathrm{~g} / \mathrm{ml}$


observed in the presence of $5 \mathrm{mM}$ cysteine. ${ }^{* * *}$ and $\# \#$ : Statistically significant difference from the untreated contraction (paired $t$-test) and FPL 55712 (unpaird $t$ test), respectively, at $\mathrm{P}<0.001$. 


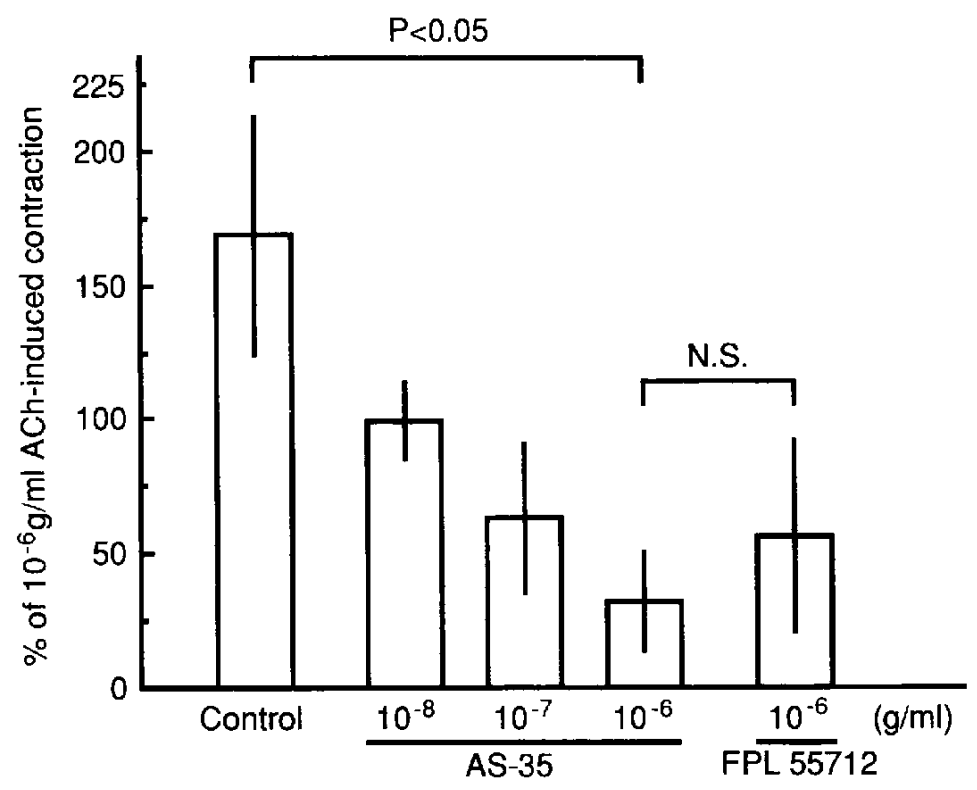

Fig. 2. Effect of AS-35 and FPL 55712 on LTD $_{4}$-induced contraction of isolated human bronchus. Each drug was added 5 min before treatment with $10^{-8} \mathrm{~g} / \mathrm{ml} \mathrm{LTD}_{4}$. Each column represents the mean \pm S.E. of 3 experiments. *: Statistically significant difference from the control at $\mathrm{P}<0.05$ (paired $t$-test). ACh: Acetylcholine.

tion-dependent relaxation at $10^{-8}-10^{-6} \mathrm{~g} / \mathrm{ml}$; and the degree of the relaxation was about $20 \%$ at $10^{-8}$ $\mathrm{g} / \mathrm{ml}, 30 \%$ at $10^{-7} \mathrm{~g} / \mathrm{ml}$ and $50 \%$ at $10^{-6} \mathrm{~g} / \mathrm{ml}$. The extent of bronchial relaxation by $10^{-6} \mathrm{~g} / \mathrm{ml}$ of FPL 55712 was similar to that by the same concentration of AS-35. The result of one out of 2 experiments is depicted in Fig. 3.

Effects on the antigen-induced contraction: Figure 4 represents the results of the inhibitory effect of AS-35 on the antigen-induced contraction $\left(5 \times 10^{-6} \mathrm{~g} / \mathrm{ml}\right.$ mite extract antigen) of the isolated human bronchus.

Pretreatment of AS-35 at concentrations of $10^{-8}$ $10^{-6} \mathrm{~g} / \mathrm{ml}$ inhibited the contraction at $10-60 \mathrm{~min}$ after the antigen challenge in a concentration-dependent fashion with or without significance. Although $10^{-6}$ $\mathrm{g} / \mathrm{ml}$ FPL 55712 also significantly inhibited the reaction at 20-60 min, the inhibition was somewhat inferior to AS-35 though without significance.

Effects on the release of histamine and LTS from passively sensitized lung fragments

The influence of the drugs on the release of histamine and LTs from the passively sensitized human lung fragments were studied. Table 2 shows the respective results of 2 different experiments.

AS-35 appeared to concentration-dependently inhibit the anaphylactic histamine and $\mathrm{i}-\mathrm{LTC}_{4}$ release at $10^{-6}$ and $10^{-5} \mathrm{~g} / \mathrm{ml}$ in either case. However, at $10^{-7} \mathrm{~g} / \mathrm{ml}$, the compound could no longer inhibit histamine release (inhibition: -5 and $-3 \%$ in 2 separate experiments,

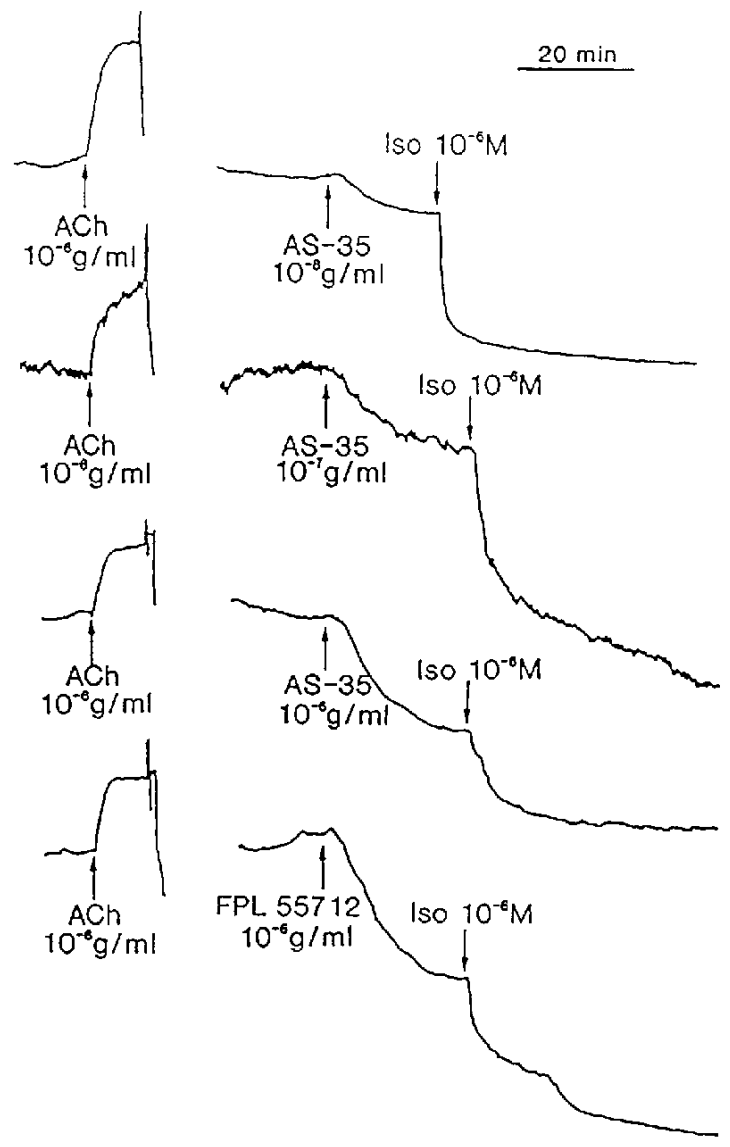

Fig. 3. Effect of AS-35 and FPL 55712 on the resting tonus of the isolated human bronchus. ACh: Acetylcholine, Iso: Isoproterenol. 


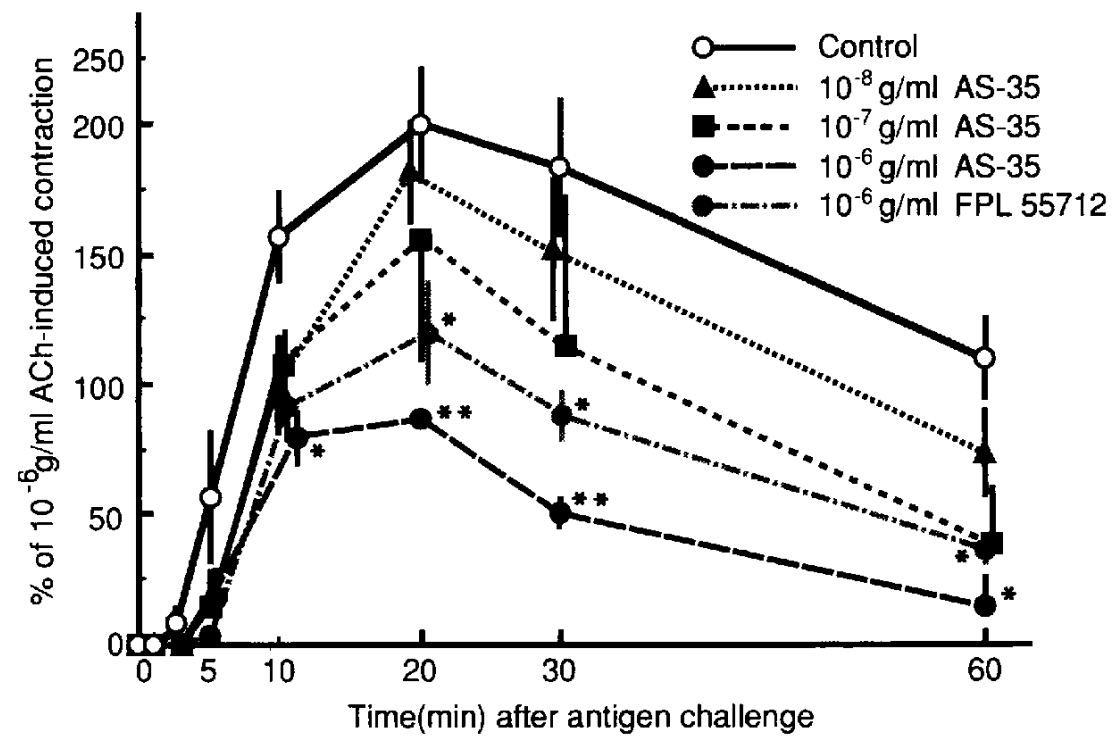

Fig. 4. Effect of AS-35 and FPL 55712 on antigen-induced contraction of the isolated human bronchus. Each drug was added $5 \mathrm{~min}$ before the challenge with $5 \times 10^{-6} \mathrm{~g} / \mathrm{ml}$ of antigen. Each point represents the mean $\pm \mathrm{S}$.E. of 3 experiments. ${ }^{*}$ and ${ }^{* *}$ : Statistically significant difference from the control at $\mathrm{P}<0.05$ and 0.01 (paired $t$-test), respectively.

Table 2. Effect of AS-35, FPL 55712 and disodium cromoglycate (DSCG) on the releases of histamine, immunoreactive (i-) $\mathrm{LTB}_{4}$ and $\mathrm{i}-\mathrm{LTC}_{4}$ from the passively sensitized human lung fragments

\begin{tabular}{|c|c|c|c|c|}
\hline \multirow{2}{*}{ Exp. No. } & \multirow{2}{*}{ Drugs $(\mathrm{g} / \mathrm{ml})$} & \multicolumn{3}{|c|}{$\begin{array}{l}\text { Amount of mediator release, } \mu \mathrm{g} \text { or } \mathrm{ng} / \mathrm{g} \text { wet tissuc } \\
\qquad(\% \text { of inhibition) }\end{array}$} \\
\hline & & $\begin{array}{l}\text { Histamine } \\
\qquad \mu \mathrm{g}\end{array}$ & $\begin{array}{c}\mathrm{i}-\mathrm{LTB}_{4} \\
\mathrm{ng}\end{array}$ & $\begin{array}{c}\mathrm{i}-\mathrm{LTC}_{4} \\
\mathrm{ng}\end{array}$ \\
\hline \multirow{7}{*}{1} & Spontaneous & 0.22 & 2.12 & 3.3 \\
\hline & Control & 0.65 & 3.32 & 16.5 \\
\hline & AS-35 $\left(10^{-6}\right)$ & $0.52(30)$ & $2.16(97)$ & $10.7(44)$ \\
\hline & AS-35 $\left(10^{-5}\right)$ & $0.42(53)$ & $2.52(67)$ & $7.0(72)$ \\
\hline & FPL $55712\left(10^{-6}\right)$ & $0.52(30)$ & $2.80(43)$ & $9.0(57)$ \\
\hline & FPL $55712\left(10^{-5}\right)$ & $0.45(47)$ & $2.56(63)$ & $5.6(83)$ \\
\hline & $\operatorname{DSCG}\left(10^{-5}\right)$ & $0.43(51)$ & $2.08(100)$ & $15.7(6)$ \\
\hline \multirow{7}{*}{2} & Spontaneous & 0.44 & 0.51 & 3.0 \\
\hline & Control & 4.73 & 3.63 & 168.1 \\
\hline & AS-35 $\left(10^{-6}\right)$ & $3.67(25)$ & $3.23(13)$ & $74.1(57)$ \\
\hline & AS-35 $\left(10^{5}\right)$ & $2.59(50)$ & $1.74(61)$ & $59.9(66)$ \\
\hline & FPL $55712\left(10^{-6}\right)$ & $3.24(32)$ & $2.10(49)$ & $86.7(49)$ \\
\hline & FPL $55712\left(10^{-5}\right)$ & $3.83(35)$ & $3.16(15)$ & $124.6(26)$ \\
\hline & $\operatorname{DSCG}\left(10^{-5}\right)$ & $3.35(21)$ & $3.60(1)$ & $89.7(47)$ \\
\hline
\end{tabular}

Drugs were added 5 min before the antigen challenge. Histamine content in the tissue was 6.76 (Exp. 1) and 2.64 (Exp. 2) $\mu \mathrm{g} / \mathrm{g}$ wet tissue. Pcrcent inhibition, shown in parentheses, of anaphylactic mediator release by the drug was calculated by the following formula: $\%$ of inhibition $=[1-$ (antigen-induced release under the presence of drug - spontaneous release)/antigen-induced release without drug (Control) - spontaneous release) $] \times 100$.

respectively). The $\mathrm{i}-\mathrm{LTB}_{4}$ release was inhibited by the same concentrations of the drug as well, although concentration-dependent inhibition was not observed in
Exp. 1. Either DSCG at $10^{-5} \mathrm{~g} / \mathrm{ml}$ or FPL 55712 at $10^{-6}$ and $10^{-5} \mathrm{~g} / \mathrm{ml}$ inhibited the release of these mediators. 


\section{DISCUSSION}

In the present experiments, it was demonstrated that AS-35 antagonized the contraction of not only isolated human bronchi but also guinea pig trachea induced by $\mathrm{LTD}_{4}$. The compound has been also reported to inhibit the binding of $\mathrm{LTD}_{4}$ to guinea pig crude lung membrane preferentially (11). Therefore, from the present results and the previous report on the binding assay, it is strongly suggested that the inhibitory effect of AS-35 on the contraction of isolated human bronchi and guinea pig tracheas by $\mathrm{LTD}_{4}$ results from competitive antagonism of the drug with $\mathrm{LTD}_{4}$ on the receptor.

In addition to the antagonism to $\mathrm{LTD}_{4}$-induced contraction, AS-35 showed the concentration-dependent inhibition of both anaphylactic histamine release and LT release from human lung fragments. The inhibitory effect of the drug on the mediator release is not likely to be linked to the $\mathrm{LTD}_{4}$-receptor antagonism. Provided that the positive but not negative feedback regulation by the released LTs exists in the following further histamine and LT release, the pretreatment with AS-35 must resultantly diminish the amount of these mediators. However, we have previously reported that a selective 5-lipoxygenase inhibitor, AA-861, does not influence the anaphylactic histamine release from human lung fragments even at high concentrations which almost completely inhibited the LT formation (12), indicating that LTs formed in or released from the mast cell do not act as the modulator of histamine release. No differences in regard to the inhibitory concentrations of AS-35 between histamine and LT release was observed. Accordingly, the inhibitory mechanism of AS-35 on the anaphylactic histamine and LT releases may not involve an action on the $\mathrm{LT}$ receptors, but must be due to the inhibition of a site(s) in the common pathway leading to the releases of histamine and LTs. FPL 55712 may also share these characteristics of AS-35 because the compound antagonized the LTD $_{4}$-induced contractions of isolated human bronchi and inhibited the anaphylactic chemical mediator release from the lung fragments as well.

AS-35 and FPL 55712 lowered the resting tonus of isolated human bronchi. It has been reported that FPL 55712 caused the elevation of intracellular cyclic adenosine monophosphate (cAMP) levels by inhibition of cAMP-dependent phosphodiesterase (13). It is also well-known that the elevation of cAMP induces the relaxation of the airway smooth muscle. Therefore, AS35 is likely to lower the resting tonus through the same mechanism as FPL 55712. In spite of this report, recent experiments in our laboratory strongly suggested that spontaneously formed p-LTs in the isolated bronchial tissue largely contribute to maintenance of the resting tonus because the spontaneous tonus is greatly lowered by a potent and selective p-LT antagonist, MCI-826, which does not inhibit the anaphylactic histamine and LT releases from the human lung in vivo (14), and a 5lipoxygenase inhibitor, AA-861, at low concentrations (data not shown). If the above-described results and the lack of an inhibitory effect by AS-35 at $10^{-7} \mathrm{~g} / \mathrm{ml}$ on anaphylactic histamine release are taken into consideration, the decreasing of the resting tonus and the inhibitory tendency of antigen-induced contraction of the human bronchus by low concentrations of AS-35 such as $10^{-8}$ and $10^{-7} \mathrm{~g} / \mathrm{ml}$, may not be due to the elevation of cAMP but mainly due to the antagonism of the compound towards p-LTs formed spontaneously and anaphylactically, respectively.

Taken together these results, AS-35 is expected to be a beneficial, orally active drug for the treatment of bronchial asthma because the compound can antagonize LT-induced contractions and inhibit chemical mediator release and bronchodilation.

\section{REFERENCES}

1 Dahlến, S.-E., Hansson, G., Hedquvist, P., Björck, T., Granström, E. and Dahlén, B.: Allergen challenge of lung tissue from asthmatics elicits bronchial contraction that correlates with the release of leukotriene $C_{4}, D_{4}$ and $E_{4}$. Proc. Natl. Acad. Sci. U.S.A. 80, 1712-1716 (1983)

2 Dahlén, S.-E., Hedquist, P., Hammarström, S. and Samuelsson, B.: Leukotrienes are potent constrictors of human bronchi. Nature 288, 484-486 (1980)

3 Ueno, T., Tanaka, K., Katori, M., Hayashi, M. and Arai, $Y$.: Species difference in increased vascular permeability by synthetic leukotriene $\mathrm{C}_{4}$ and $\mathrm{D}_{4}$. Prostaglandins 21, 637-648 (1981)

4 Johnson, H.G. and McNee, M.L.: Secretagogue responses of leukotriene $\mathrm{C}_{4}, \mathrm{D}_{4}$ : Comparison of potency in canine trachea in vivo. Prostaglandins 25, $237-243$ (1983)

5 Augstein, J., Farmer, J.B., Lee, T.B., Sheard, P. and Tattersall, M.L.: Selective inhibitor of slow reacting substance of anaphylaxis. Nature (New Biol.) 245, 215-217 (1973)

6 Sheard, P., Lee, T.B. and Tattersall, M.L.: Further studies on the SRS-A antagonist, FPL 55712. Monogr. Allergy 12, $245-249(1977)$

7 Kasai, H., Kawashima, T., Omura, S. and Yanagihara, Y.: Peptide leukotriene antagonistic activity of AS-35, a new antiallergic drug. Japan. J. Pharmacol. 58, 347-355 (1992)

8 Watanabe-Kohno, S., Shimizu, T., Mizuta, J., Ogino, K., Yamamura, H. and Ohata, K.: Effect of procaterol on the isolated airway smooth muscle and the release of anaphylactic chemical mediators from the isolated lung fragments. Arzneimittleforschung 40, 669-674 (1990)

9 May, C.D., Lyman, M., Alberto, R. and Cheng, J.: Procedures for immunochemical study of histamine release from leukocytes with small volume of blood. J. Allergy 46, 12-20 
(1970)

10 Kohno, S.W., Hashii, H., Ogino, K., Yamamura, H. and Ohata, K.: Effect of oxitropium bromide (Ba253) on isolated respiratory smooth muscle and release of chemical mediators from passively sensitized lung fragments. Japan. J. Pharmacol. 50, 207-216 (1989)

11 Kasai, $H$. and Yanagihara, Y.: Inhibition of radiolabeled leukotriene-binding by AS-35 in the guinea pig lung membrane fraction. Japan. J. Pharmacol. 58, 357-364 (1992)

12 Yamamura, H., Taira, M., Negi, H., Nanbu, F., Kohno, S.W. and Ohata, K.: Effect of AA-861, a selective 5-lipoxy- genase inhibitor, on models of allergy in several species. Japan. J. Pharmacol. 47, $261-271$ (1988)

13 Casin, M. and Scott, C.: Inhibition of cyclic nucleotide phosphodiesterase by FPL 55712, an SRS-A antagonist. Biochem. Pharmacol. 27, 2065-2067 (1978)

14 Kohno, S., Nabe, T., Yamamura, H., Horiba, M. and Ohata, K.: Regulation of leukotriene generation. In the Symposium of Modulation of Chemical Mediator Release at XVI International Congress of Allergology and Clinical Immunology (Kyoto), Prog. Allergy Immunol. (in press) 